\title{
Coupling of an individual-based model with a complex aquatic ecosystem model to explore the impact of the upper trophic level on lower trophic levels
}

\author{
$\underline{\text { Vardit Makler-Pick }}^{a}$, Gideon Gal ${ }^{\text {b }}$ and Matthew R. Hipsey ${ }^{c}$ \\ a. Oranim Academic College of Education, Kiryat Tivon 36006, Israel \\ b. Y. Allon Kinneret Limnological Laboratory, Israel Oceanographic \& Limnological Research, \\ P.O. Box 447, Migdal 14950, Israel \\ c. School of Earth and Environment, The University of Western Australia, \\ 35 Stirling Highway, Crawley WA 6009, Australia.
}

\section{Email:vardit@,oranim.ac.il}

\begin{abstract}
This article demonstrates an attempt to benefit from the merging of different modeling approaches. A complex aquatic ecosystem model (DYRESM-CAEDYM, DYCD) was coupled to a super individual-based model that simulates a fish population. The coupled model, DYCD-FISH, is a generic model that simulates the fish populations in aquatic systems and their impacts on water quality and lower trophic levels. The model reproduces fish growth and predicts fish impacts on various ecosystem components, including nutrients, phytoplankton, zooplankton, intra- and inter-species dynamics. The coupled model was employed to explore the role of the dominant fish in Lake Kinneret (Israel), Acanthobrama terraesanctae (lavnun). Model results suggested that the lavnun has a significant impact on the density of its prey food (predatory and micro-zooplankton) and on the concentration of major nutrients such as ammonium (NH4) and phosphate (PO4). The merging of the two modeling approaches also provided a means for simulating the intra-guild predation (IGP) dynamics in the lake. The results indicated that predation pressure of predatory zooplankton on herbivorous zooplankton varied widely with season exerting, at the time of its annual peak, an average predation pressure 10-20 times higher than the lavnun. The results presented in the study successfully demonstrated how the linking of various modeling approaches can reveal the nonlinear trophic interaction dynamics within ecosystems.
\end{abstract}

Keywords: $\quad$ Integrated modeling approaches, DYCD-FISH, Complex dynamic model, Individual-based model, Lake Kinneret. 


\section{INTRODUCTION}

Models have proven valuable for understanding the possible outcome of postulated interactions in ecosystems (Canham et al., 2003). The large number of lake ecosystem models published in recent years acknowledge the great importance of lake ecosystems for society and indicates the increasing interest in understanding and capturing essential processes in lakes (Jørgensen 2010). The interactions between biotic and abiotic components of lake ecosystems, the status of each one of them and the processes involved (for instance, eutrophication), can be encompassed and represented by adapting a complex dynamic modeling approach. Such an approach has been demonstrated in many popular models such as CE-QUAL-W2, Delft 3D-ECO, LakeWeb, CAEDYM and PCLake. There are also examples of complex models that have successfully integrated knowledge across several trophic levels of the ecosystem (Rose et al. 2007). Yet, these models typically use only a one or two (epilimnion/hypolimnion) physical compartments not always adequate to represent water column stratification, or, exclusively simulate the lower trophic levels (Chen et al. 2002). Only a limited number of them (e.g., Megrey et al. 2007) allow full feedbacks and dynamic interactions among all various components.

Another modeling approach that allows the explicit inclusion of individual variation in greater detail than do classical population models is the individual-based model (IBM, DeAngelis and Mooij 2005). In this approach individuals are modeled separately being different from each other in their characteristics (e.g., size, weight, age). For modeling large populations, it is typically too computationally demanding to model all individuals in the ecosystem. A more efficient approach is the 'super-individual model' (Scheffer et al. 1995). The super-individual approach follows the development of an individual-based model where each 'super individual' represents numerous similar individuals. This approach has been applied, for example, in the macrophyte model Charisma (Van Nes et al. 2003) and the fish model Piscator (Van Nes et al. 2002). Piscator, for instance, has eight interacting fish species, three types of fisheries, piscivorous birds but only a simple presentation of the fish food (zooplankton, benthos). However, for the purpose of assessing the impacts of the higher trophic level on lower trophic levels, on inter and intra species interactions, and on water quality, a comprehensive model is essential.

A single modeling approach can not encompass all ecosystem components at all scales of time and space (Mooij et al. 2010). Moreover, each modeling approach has a specific function and limitations and even complex ecosystem models will never provide perfect predictions or be absolutely accurate. It is possible however to improve the models by integrating different approaches. This perception merges some of the advantages and eliminates some of the disadvantages of the existing models. Barrio et al. (2006), for example, has shown that addressing more localized impacts of climate change requires integrated modeling approaches which also address fine-scale processes. The challenge of developing an integrated model involves the understanding of the properties of the different models, and the dynamic linking over different time and space scales that are essential for their coordination and effective use.

The impact of fish on lake ecosystem food webs has been extensively investigated and it is well established that fish can directly or indirectly affect biological and chemical components of lake ecosystems (Jeppesen et al. 2005; Gozlan et al. 2010). The study described in this paper aims to addresses the knowledge gaps related to the impact the fish have on lower trophic levels and water quality, by adapting an approach that integrates a complex aquatic ecosystem model (DYCD) with a super individual-based fish model. The integrated model, DYCD-FISH, allowed exploration of the impact of the dominant fish in Lake Kinneret (Israel), Acanthobrama terraesanctae (Kinneret bleak, local name lavnun) on various ecosystem components (including nutrients, phytoplankton and zooplankton) and the revealing of intra- and inter-species dynamics in the lake.

\section{MODEL APPROCH}

\subsection{DYRESM-CAEDYM (DYCD) - A complex ecosystem model}

DYCD couples the 1D hydrodynamic model, DYRESM, and the aquatic ecological model CAEDYM. DYRESM is a laterally averaged Lagrangian code for predicting the vertical stratification and mixing dynamics in lakes and reservoirs (Imberger and Patterson 1989). The model also includes pseudo-2D processes such as benthic boundary layer mixing. Based on the inflows, withdrawals, and meteorological conditions, DYRESM calculates the changes to the water level and changes in water temperature and salinity (and hence density) over depth and time. The model outputs are the drivers of the Computational Aquatic Ecosystem DYnamic Model (CAEDYM, Gal et al. 2009). CAEDYM is a process-based library of water quality, biological and geochemical sub-models. The recent version of CAEDYM simulates suspended solids, oxygen, organic and inorganic nutrients $(\mathrm{C}, \mathrm{N}, \mathrm{P}$ and $\mathrm{Si}$ ), multiple phytoplankton functional groups, 
zooplankton, benthic biological communities (macroalgae, macrophytes and benthic invertebrates), pathogens, geochemistry (including ions, $\mathrm{pH}$, redox and metals), and sediment oxygen, nutrient and metal fluxes. These are represented by a long series of mass conservative coupled differential equations. The ecosystem representation is configurable and can be varied by the user depending on the purpose of the model and the availability of data.

\subsection{Individual-based model}

The super individual-based model that simulates the fish population was based on sets of individual-based models that employed the "Wisconsin" bioenergetics equation (Ney 1993) with specific parameters to account for the metabolism and growth of different age groups. The bioenergetics equation simulates the daily changes in wet weight per unit of weight per day $\left(g_{w w} \cdot g_{f i s h}{ }^{-1} \cdot d_{a y}{ }^{-1}\right)$ that occurs through consumption, respiration, excretion, egestion, specific activity, and reproduction, assuming that the change in weight is equal to the difference between the consumption and loss of energy. The growth rate of an individual fish is calculated as weight increment per unit of weight per time increment and is defined by:

$$
\frac{1}{W} \frac{d W}{d t}=[C-(R+S+F+E+P)]\left[\frac{C A L_{\text {prey }}}{C A L_{\text {fish }}}\right]
$$

where $\mathrm{C}$ is consumption, $\mathrm{R}$ is respiration, $\mathrm{S}$ is specific dynamic activity, $\mathrm{F}$ is egestion, $\mathrm{E}$ is excretion, $\mathrm{P}$ is reproduction, $\mathrm{W}$ is wet weight of the fish $(\mathrm{g})$ and $\mathrm{CAL}_{\text {prey }} / \mathrm{CAL}_{\text {fish }}$ is the caloric equivalence for converting caloric equivalence of food to caloric equivalence of fish. Consumption, respiration, specific dynamic activity, excretion, egestion, and reproduction are in units of $\mathrm{g}_{\text {prey }} \cdot \mathrm{g}_{\text {fish }}{ }^{-1} \cdot \mathrm{day}^{-1}$, which are converted to $\mathrm{g}_{\text {fish }} \cdot \mathrm{g}_{\text {fish }}{ }^{-1} \cdot \mathrm{day}^{-1}$ by the ratio of the prey to fish energy densities. To simulate the fish population, the bioenergetics equation (eq. 1) was applied to numerous individual fish. The individuality of each fish was created through a behavioral sub-model that reallocated each fish within the water column dependent on criteria related to oxygen, temperature, light, and food. This serves to expose each fish to a unique history of biotic and abiotic environmental conditions. In addition, each fish was "genetically different" from the other fish, since it acquired individual random values, within a defined range, of the parameters for the weightlength relationship. Other bioenergetics parameters were not individualized and were common to the entire population. As it was not practical to simulate the entire fish population as individual computational units, a set of "representative fish" were used to aggregate a number of similar fish into a single computational entity. The number of representative fish changed dynamically during the simulation according to simulated processes of recruitment and natural and fishing mortality.

\subsection{DYCD-FISH}

To simulate the interactions among the hydrodynamics, biogeochemistry, phytoplankton, zooplankton, and fish, DYCD was used as the model platform to which a super individual-based fish population model was coupled, creating a new combined ecosystem-fish model, DYCD-FISH. The integrated model accounted for the direct and indirect feedbacks between fish and the biogeochemical and planktonic components of the ecological model (see Makler-Pick et al. 2011, for a detailed description of DYCD-FISH). The models can run statically (no feedbacks engaged, e.g. 'static mode'), but when dynamically coupled (e.g. 'dynamic mode'), the mass of carbon and nutrients are tracked between the models, and the combined DYCD-FISH model accounts for the direct and indirect feedbacks between fish and the biogeochemical and planktonic components in the ecological model. Comparing between the static model (where fish feedbacks are not engaged) and the dynamic model (where feedbacks are implemented) allows exploring the inclusive effect of the lavnun on lower trophic levels and water quality.

\section{STUDY SITE}

Lake Kinneret (Sea of Galilee) is a large monomictic lake located in the Syrian-African Rift Valley in northeastern Israel. It covers an area of $170 \mathrm{~km}^{2}$, it is $22 \mathrm{~km}$ long, $12 \mathrm{~km}$ wide, and has a maximum depth of $43 \mathrm{~m}$. Lake Kinneret is of critical importance since it supplies about $30 \%$ of Israel's drinking water. Lake Kinneret is considered as meso-eutrophic with a mean annual primary production of $650 \mathrm{gCm}^{-2}$ (Berman et al. 1995). Since the mid-1990's the lake ecosystem has undergone a number of significant changes (Zohary and Ostrovsky 2011, Gal and Anderson 2010). For further information on the lake, the reader is referred to Serruya (1978) and Berman et al. (1995).

\subsection{Acanthobrama terraesanctae (lavnun)}

The lavnun is the dominant fish in Lake Kinneret. For more then two decades (1970-1993) the lavnun constituted an important share of the Lake Kinneret commercial fishery with a fairly constant catch of 900- 
$1000 \mathrm{t} \mathrm{y}^{-1}$. However, following exceptionally heavy floods in the winter of 1991/92 and again in 2002/03, that caused unusual increases in the lake's water level, the lavnun fishery collapsed as the population became devoid of individuals of commercially harvestable sizes (>12 cm, Hambright and Shapiro, 1997). Yet, hydroacoustic surveys indicated that the abundance of fish in Lake Kinneret (mainly sub-commercial sized lavnun) in 1993 and again in 2004 increased by 8-10 fold in comparison to fish abundance levels prior to the flood years (Zohary and Ostrovsky 2011). These exceptional increases in fish density were the consequence of unusually successful recruitment of lavnun, as a result of the extreme water level increases in a single winter that created a larger area of littoral spawning grounds. The diet composition of the lavnun includes predatory zooplankton, herbivorous zooplankton, micro-zooplankton, and particulate detrital material. However, the impact of the lavnun abundance on the food web and water quality is still unclear.

\subsection{Intra-guild predation (IGP) in Lake Kinneret}

The IGP component in the Lake Kinneret food web consists of the dominant fish in the lake - the zooplanktivorous lavnun, and predatory invertebrates (adult cyclopoid copepods); both feed on herbivorous zooplankton, while the fish also feed on the adult cyclopoid copepods (Fig. 1). Blumenshine and Hambright (2003) compared the potential predation pressure on Lake Kinneret herbivorous zooplankton by lavnun with that by the cyclopoid copepods Mesocyclops ogunnus and Thermocyclops dybowskii. Their results indicated that despite having a much lower biomass, adult cyclopoid copepods accounted for a greater portion of the predation mortality on herbivorous zooplankton than the lavnun, which suggested that any reductions in predation pressure of lavnun (for example by removal of fish) would not result in a subsequent increase in herbivorous zooplankton biomass as expected according to top-down theory. Moreover, a reduction in lavnun predation pressure may allow for increases in cyclopoid copepod abundance and thereby result in a net increase in the predation pressure on herbivorous zooplankton.

\section{MODEL SETUP AND VALIDATION}

DYCD version 2.3, previously calibrated for Lake Kinneret (Gal et al. 2009), was set to simulate the carbon, nitrogen, phosphorus, and oxygen cycles along with the biomass and metabolic processes of five phytoplankton groups (Peridinium gatunense, Aulacoseira granulate, Aphanizomenon sp., Microcystis sp., and a general group, termed nanoplankton), three zooplankton functional groups (predatory zooplankton adult stages of the predatory copepods and predatory rotifers; herbivorous zooplankton - cladocerans, copepodites; micro-zooplankton), and heterotrophic microbial loop dynamics of Lake Kinneret. The lakewide fish population was initialized with 1000 'representative fish', with each set to represent 100,000 fish in the lake, equating to $100,000,000$ fish in total (Walline et al., 1992). Each 'representative fish' has a record with fields such as age (day), wet weight $(\mathrm{g})$, location in water column, length $(\mathrm{cm})$, the parameters of the weight-length allometric equation, total daily consumption $\left(\mathrm{g}_{\text {prey }} \cdot \mathrm{g}_{\text {fish }}{ }^{-1} \cdot \mathrm{day}^{-1}\right)$ and the daily consumption of each of the various prey types $\left(\mathrm{mgC} \cdot \mathrm{L}^{-1} \cdot\right.$ day $\left.^{-1}\right)$. The simulated variables of the fish sub-model include length-weight data, length at age, weight at age, total biomass, total fish number, population size-distribution and fish predation rate on zooplankton. The model simulations were configured to run from January 1997 to September 2003. The base model was run with a $1 \mathrm{~h}$ time step and daily output. A daily time step was used for the fish model to reduce simulation time (see Makler-Pick et al. 2011). The calibration and validation of the lavnun model was based on data from different sources, mainly the routine monitoring of the catch and size analysis (weight and length). To determine the impact of the lavnun on water quality we visually, and statistically (Student's t test, McDonald 2009), compared between the static and dynamic models using values of simulated state variables, such as zooplankton biomass, inorganic nitrogen and phosphorus as the basis for the comparison. To simulate IGP dynamics when the number of fish is higher than the multiannual average, a series of scenarios were conducted where the number of the fish represented by each "representative" super-individual was changed. The fish number was changed from an initial number of 100,000 (x1, base level) to 200,000 (x2) and up to 800,000 (x8) per "representative" fish. Based on the outcome of the scenarios we studied the impact of fish abundance on nutrients, phytoplankton and zooplankton biomass.

\section{RESULTS AND DISCUSSION}

The effect of the fish on the mean monthly concentration of several state variables and the statistical difference between the static model and the dynamic model were evaluated. The results indicate a significant impact $(p<0.05)$ of the base level of the fish on state variables such as the predatory and micro-zooplankton (Fig. 2), NH4, total nitrogen (TN), $\mathrm{PO}_{4}$ and total phosphorus (TP, Fig. 3) in the 10 top meters of the water column. 
The predation pressure by both the lavnun and the predatory zooplankton, (e.g. the IGP-predator and the IGP prey, respectively) varied seasonally, imposing predation pressure of the predatory zooplankton 10-20 times higher than the lavnun predation pressure during the winter and early spring (Fig 4). It can therefore be concluded that during these seasons predatory zooplankton (and not the lavnun) control herbivorous predation when fish abundance is similar to the multi-annual average. The zooplankton predation rate is comparable to the results published by Blumenshine and Hambright $\left(2003,921 \mathrm{mg}_{\text {prey }} \mathrm{g}_{\text {pred }}{ }^{-1}\right.$ day $^{-1}$ in comparison to $1129 \mathrm{mg}_{\text {prey }} \mathrm{g}_{\text {pred }}{ }^{-1}$ day $^{-1}$ as simulated with DYCD-FISH) that also reported an average consumption rate on herbivorous zooplankton by cyclopoid copepods, an order of magnitude higher than fish predation.
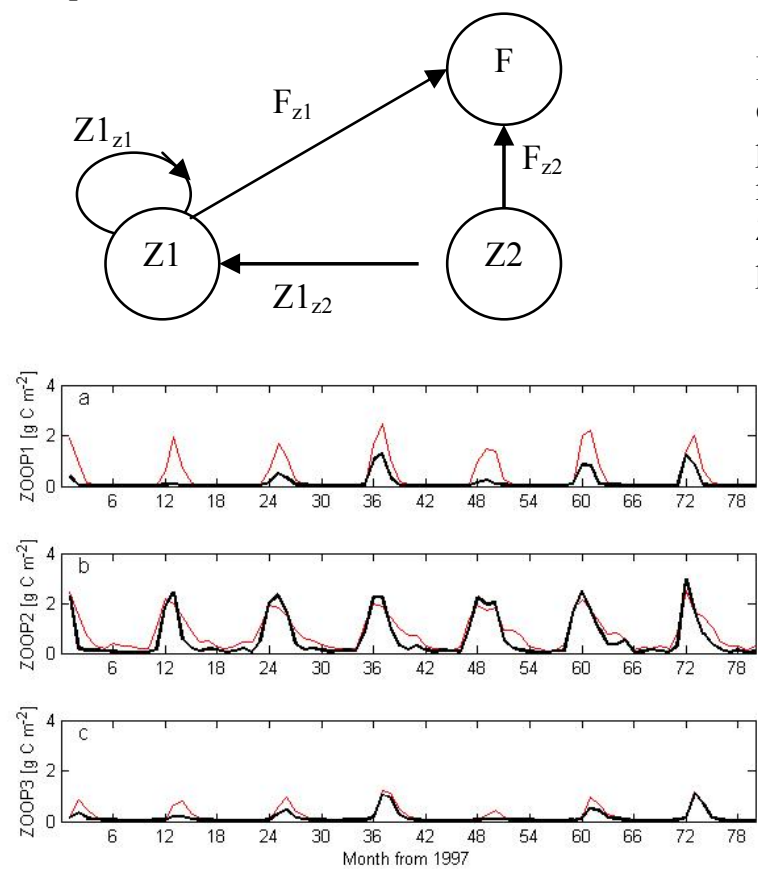

Figure 2: Dynamic (black line) and static model (red line) mean monthly values for (a) predatory zooplankton, (b) herbivorous zooplankton, (c), and

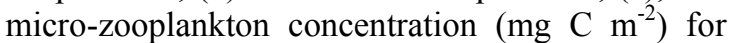
the top $10 \mathrm{~m}$ of the water column over a period of 80 months (Jan 1997-Sep 2003).
Figure 1: Schematic food web in an aquatic ecosystem containing an IGP component. F, Z1, and Z2 are fish, predatory zooplankton and herbivorous zooplankton, respectively. $F_{z 1}$ and $F_{z 2}$ are fish predation rates on $Z 1$ and $Z 2$, respectively. $Z 1_{z 1}$ and $Z 1_{z 2}$ are $Z 1$ predation rates on predatory and herbivorous zooplankton, respectively.

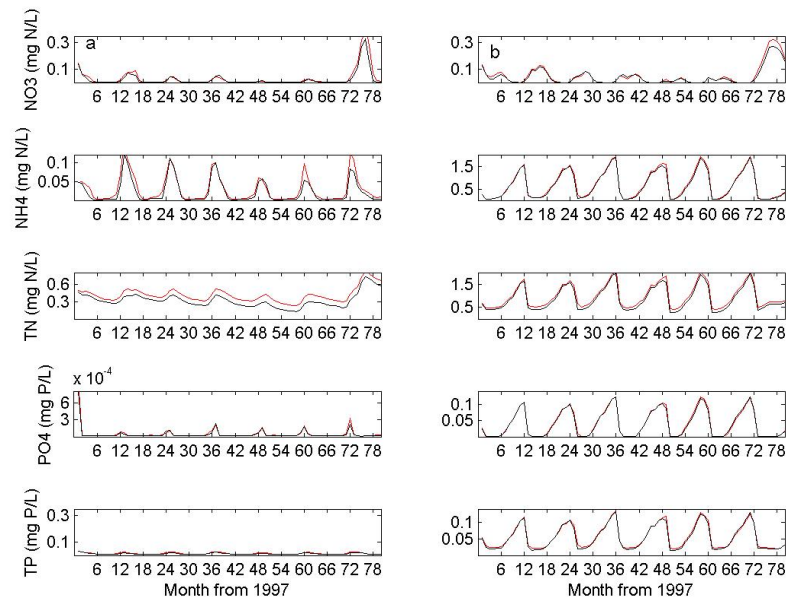

Figure 3: Mean monthly values for $\mathrm{NO}_{3}, \mathrm{NH}_{4}, \mathrm{TN}$, $\mathrm{PO}_{4}$ and TP concentration simulated by the dynamic model (black line) in comparison to the static model (red line), (a) at the 10 top meters of the water column, and (b) at the 10 bottom meters of the water column over a period of 80 months (Jan 1997-Sep 2003).

There is a substantial impact of the fish on the ecosystem that is well demonstrated in the presence of 8 times more fish (such an increase in abundance of the lavnun fish was documented after an atypical meteorological year). In the presence of 8 times more fish there was a considerable ( $>20 \%$ on average) impact on TN and phytoplankton, such as Microcystis sp. (Fig. 5) and a significant (35\%) decrease in the mean biomass of herbivorous zooplankton over the whole simulation period, however the main impact on herbivorous zooplankton was limited to the periods between the seasonal biomass peaks (Fig. 6). Interestingly, during the seasonal biomass peaks of herbivorous zooplankton their concentration, in the presence of 8 times more fish, were similar or even higher than the concentrations simulated with the base level of fish. This finding illustrates how, at high numbers of fish, the system seasonally shifts between being dominated by fish (when the food web resembles a linear food chain) to periods when the dominant effect on herbivorous zooplankton, is the substantial release from predation pressure by the predatory zooplankton.

Increasing the number of fish also imposed a considerable change in the size distribution of the fish population to a smaller-sized fish (e.g. maximum length of $12.7 \mathrm{~cm}$ in comparison to $17.2 \mathrm{~cm}$ during the base level simulation) and a higher percentage of sub-commercial size fish $(<12 \mathrm{~cm}$ length), indicating a generally lower growth rate (Fig. 7). These results are comparable to the field data measured after the winter 1991-1992: the disappearance of the large fish and the subsequent fishery collapse in 1993. 


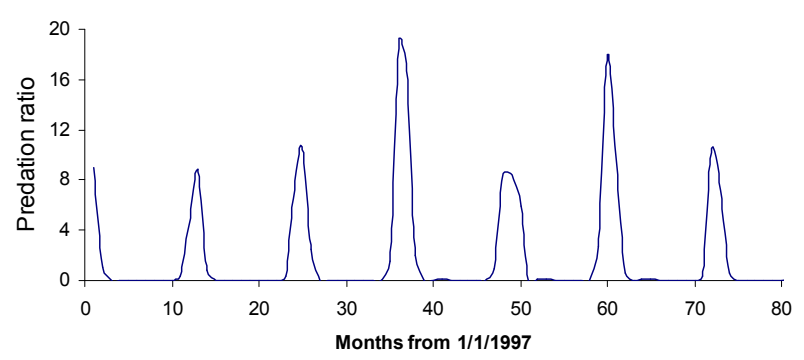

Figure 4: Average monthly ratio of zooplankton predation rate to fish predation rate, on herbivorous ${ }^{0.8}$ zoonlankton.
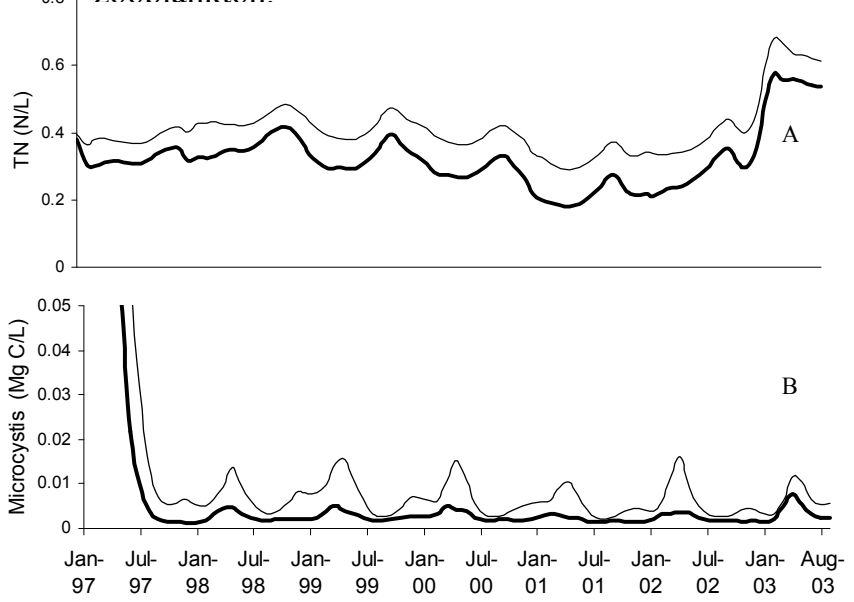

Figure 5: Concentration of Total Nitrogen (A) and Microcystis (B) at $\mathrm{x} 1$ (thin line) and $\mathrm{x} 8$ (thick line) fish)

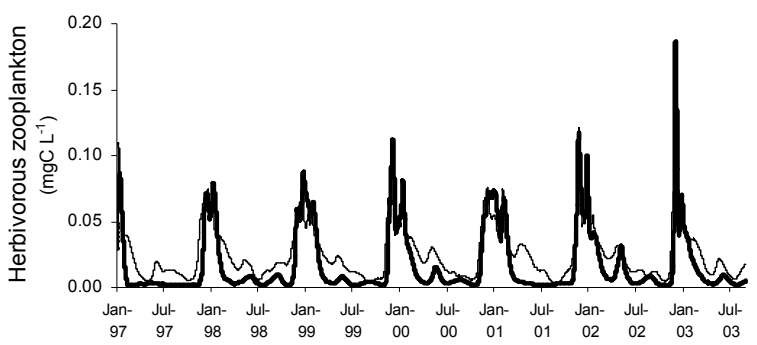

Figure 6: Concentration of herbivorous zooplankton at $\mathrm{x} 1$ (thin line) and $\mathrm{x} 8$ (thick line) fish
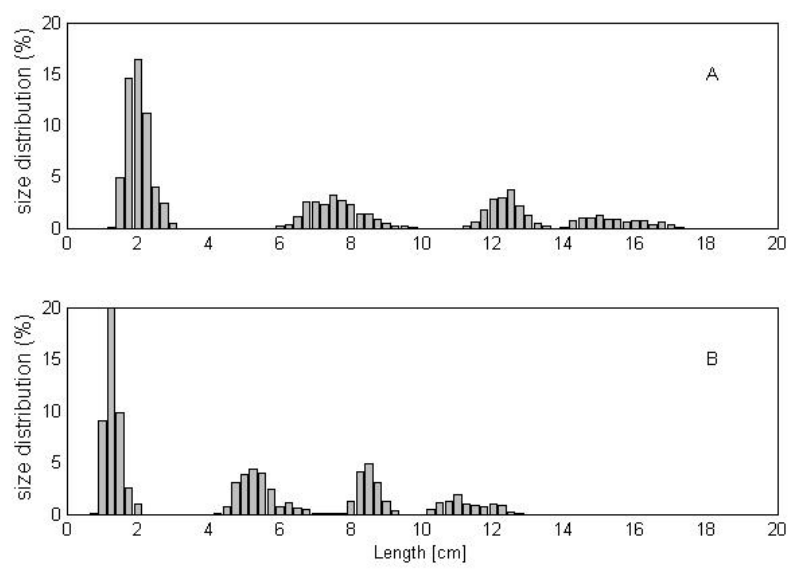

Figure 7: Simulated fish size distribution in June 2002 at (A) base level (x1) of fish, and (B) at 8 times $(\mathrm{x} 8)$ more fish

\section{CONCLUSIONS}

In this study we demonstrated an integrated modeling approach that couples a complex ecosystem model with a super individual-based model. The newly integrated model is a more realistic representation of the complexity of aquatic ecosystems, since it explicitly includes a higher trophic level, often overlooked in coupled physical-ecological models. Additionally, the model dynamically links and allows feedbacks, typically not fully modeled, between several trophic levels and the abiotic components of the ecosystem. It can therefore serve as a unique experimental system to explore the effects of the higher trophic level on other ecosystem components that otherwise, could not be explored.

Specifically for Lake Kinneret, it can be concluded that at higher than average fish abundance (e.g. 8 times more than the average) fish have a considerable impact through bottom-up and top-down effects. High fish abundance causes: 1) a decrease in TN and phytoplankton (such as Microcystis), 2) a significantly lower herbivorous zooplankton biomass related to combined direct and indirect predation pressure of fish and predatory zooplankton and 3) a shift of fish body size towards smaller sizes, resulting with most of the fish being of sub-commercial size. Fish have the potential to play an important role in nutrient cycles because they store nutrients in their tissues, transport and remineralize nutrients providing readily available nutrients to primary producers or, prey on other remineralizing organisms (such as the mico-zooplankton). The response to changes in fish abundance is dependent upon the order of change and the compensatory responses of the ecosystem.

The application of an integrated model for exploring trophic interaction dynamics within ecosystems provides a means for examining intricate system dynamics which has implications also in terms of ecosystem-based management of the lake.

\section{REFERENCES}

Barrio, G., Harrison, P.A., Berry, P.M., Butt, N., Sanjuan, M.E., Pearson, R.G. and Dawson, T. (2006). Integrating multiple modelling approaches to predict the potential impacts of climate change on species' 
distributions in contrasting regions: comparison and implications for policy. Environmental Science \& Policy, 9(2), $129-147$.

Berman, T., Stone, L., Yacobi, Y.Z., Kaplan, B., Schlichter, M., Nishri, A., and Pollingher, U. (1995). Primary production and phytoplanktonin Lake Kinneret: a long-term record (1972-1993). Limnology and oceanography, 40(6), 1064-1076.

Blumenshine, S.C. and Hambright, K.D. (2003). Top-down control in pelagic systems: a role for invertebrate predation. Hydrobiologia, 491, 347-356.

Canham, C. D., J. S. Cole, and W. K. Lauenroth (eds.) (2003). Models in Ecosystem Science. Princeton University Press, Princeton.

Chen, C., et al., (2002). A model study of the coupled biological and physical dynamics of Lake Michigan. Ecological modelling, 152, 145-168.

DeAngelis, D.L, Mooij, W.M. (2005). Individual-based models of ecological and evolutionary processes. Annual Review of Ecology and Systematics, 36, 147-168.

Gozlan, R.E., Britton, J.R., Cowx, I., and Copp, G.H. (2010). Current knowledge on non-native freshwater fish introductions. Journal of Fish Biology, 76(4), 751-786.

Gal, G., and Anderson, W. 2010. A novel approach to detecting a regime shift in a lake ecosystem. Methods in Ecology and Evolution, 1, 45-52.

Gal, G., Hipsey, M.R., Parparov, A., Wagner, U., Makler, V., and Zohary, T. 2009. Implementation of ecological modeling as an effective management and investigation tool: Lake Kinneret as a case study. Ecological modelling, 220, 1697-1718.

Hambright, K.D., and Shapiro, J. (1997). The 1993 collapse of the Lake Kinneret bleak fishery. Fisheries Management and Ecology, 4(4), 275-283.

Imberger, J., and Patterson, J.C. (1989). Physical limnology. In Advanced applied mechanics. Edited by T. Wu. Academic Press, Boston, Mass. pp. 303-475.

Jeppesen, E., M. Søndergaard, N. Mazzeo, M. Meerhoff, C. Branco, V. Huszar \& F. Scasso, 2005. Lake restoration and biomanipulation in temperate lakes: relevance for subtropical and tropical lakes. Chapter 11. In Reddy, M. V. (ed.), Tropical Eutrophic Lakes:Their Restoration and Management. Science Publishers, Enfield, 331-359.

Jørgensen, S.E. (2010). A review of recent developments in lake modelling. Ecological modelling, 221, 689692.

McDonald, J.H. (2009). Handbook of Biological Statistics, 2nd ed. Baltimore: Sparky House Publishing. Page 118.

Makler-Pick, V., Hipsey, M.R., Shapiro, J. and Gal, G. (2011). Exploring the role of fish in a lake ecosystem (Lake Kinneret, Israel) by coupling an individual-based fish population model to a dynamic ecosystem model. Canadian Journal of Fisheries and Aquatic Sciences, 68, 1265-1284.

Megrey, B.A., Rose, K.A., Klumb, R.A., Hay, D.E., Werner, F.E., Eslinger, D.L. and Smith, S.L. (2007). A bioenergetics-based population dynamics model of Pacific herring (Clupea harengus pallasii) coupled to a lower trophic level nutrient-phytoplanktonzooplankton model: description, calibration and sensitivity analysis. Ecological modeling, 20,144-164.

Mooij, W.M., Trolle, D., Jeppesen, E., et al., (2010). Challenges and opportunities for integrating lake ecosystem modelling approaches. Aquatic Ecology, 44(3), 633-667.

Rose, K.A.,Werner, F.E., Megrey, B.A., Aita, M.K., Yamanaka, Y., Hay, D.E., Schweigert, J.F., and Foster, M.B. (2007). Simulated herring growth responses in the Northeastern Pacific to historic temperature and zooplankton conditions generated by the 3-dimensional NEMURO nutrient-phytoplankton-zooplankton model. Ecological modeling, 202(1-2), 184-195.

Scheffer, M., Baveco, J.M., DeAngelis, D.L., Rose, K.A., Van Nes, E.H. (1995). Super-individuals a simple solution for modelling large populations on an individual basis. Ecological modeling, 80, 161-170.

Ney, J.J. (1993). Bioenergetics modeling today: growing pains on the cutting edge. Transactions of the American Fisheries Society, 122(5), 736-748.

Serruya C., (1978). Lake Kinneret. Dr. W. Junk, The Hague, 501 p.

Van Nes, E.H., Lammens, EHRR., Scheffer, M. (2002). PISCATOR, an individual-based model to analyze the dynamics of lake fish communities. Ecological modeling, 152, 261-278.

Van Nes, E.H., Scheffer, M., Van den Berg, M.S., Coops, H. (2003). Charisma: a spatial explicit simulation model of submerged macrophytes. Ecological modeling, 159, 103-116.

Walline, P.D., Pisanty, S., and Lindem, T. 1992. Acoustic assessment of the number of pelagic fish in Lake Kinneret, Israel. Hydrobiologia, 231(3), 153-163.

Zohary, T., and Ostrovsky, I. (2011). Ecological impacts of excessive water level fluctuations in stratified freshwater lakes. Inland Waters, 1, 47-59. 